\title{
Equity of medical research representation on the global stage: A need for change
}

\author{
Andrés Gómez-De León, Nelson J. López-Flores, and Cesar D. Galindo-Calvillo \\ Hematology Service, School of Medicine and "Dr. José E. González" University Hospital Universidad Autónoma de Nuevo León, Monterrey, Nuevo \\ Leon, Mexico
}

Scientific research is a fundamental tool for the technological development of a country. Knowledge of specific problems faced by a population is the first step in their systematic and efficient resolution. Translating these concepts into global health, medical research would ideally be dedicated to improving the quantity and quality of the lives of all human beings throughout the world in a cost-effective manner. In reality, however, socioeconomic, geographic, historical, and political differences have led to disparities in the capacity for scientific research between countries and regions. Even though more than $80 \%$ of the world's population live in low- and middle-income countries (LMIC), most scientific research is performed in high-income countries $(\mathrm{HICs})^{1}$. This problem, while often recognized, has been poorly studied.

International scientific conferences represent an interesting focus of study, where equity in global research capacity and representation can be assessed at a single point in time across disciplines. We have undertaken such a study in our field of hematology, mostly driven by curiosity, as we are LMIC investigators. We assessed all abstracts accepted to the American Society of Hematology Meeting in 2018 and selected those with an author affiliated with an LMIC institution and found surprising results; $10 \%$ of research contributions were from LMICs, most in partnership with authors from $\mathrm{HICs}$, and only $4.7 \%$ represented truly independent LMIC-originated research, with the bulk of LMIC research coming from China, Russia, Brazil, India, Turkey, and
Mexico ${ }^{2}$. We read with interest the work by Velin et al., recently published in BMJ Global Health, where the authors performed a systematic review of 46 articles describing 112 conferences from the past 30 years that reported factors associated with conference attendance and equity of representation that shows that this is true across disciplines and helps explain our initial findings. The authors show that only $39 \%$ of delegates came from an LMIC; five main groups of barriers to equity in participation were identified. The most frequently reported barrier was limited opportunity to speak, followed by financial barriers, visa restrictions, political barriers, and racism/discrimination ${ }^{3}$. The study was limited by the overall low quality of evidence due to a heterogeneous group of works (including ours), but nonetheless reflects a common sentimentacross fields: international conferences lackequal representation. This may limit the exchange of valuable and globally relevant information arising from LMICs. Facilitators that may decrease these disparities include relocating meetings to visa-friendly countries, travel scholarships, and research empowerment through mentoring and education ${ }^{3}$.

Unfortunately, the problem does not end with international conferences. Another recent systematic review published on JAMA Oncology reflects the fact that irrespective of the quality of the research performed, pervasive inequity in publication still exists. A study by Wells et al. assessed 694 Phase 3 randomized control trials (RCTs) in oncology published from 2014to 2017 and found, unsurprisingly, that

\section{Correspondence:}

*Andrés Gómez-De León MD

E-mail: andres.gomezd@uanl.edu.mx
Available online: $28-06-2021$

Date of reception: 07-03-2021

Date of acceptance: 13-04-2021

DOI: 10.24875/RMU.21000018
Medicina Universitaria. 2021;23(2):35-36 www.medicinauniversitaria.org license (http://creativecommons.org/licenses/by-nc-nd/4.0/). 
most RCTs were led by HICs (92\%) and were more likely to be funded by the pharmaceutical industry in comparison to LMICs $(73 \% \text { vs. } 41 \%)^{4}$. Although studies from LMICs were smaller, they were more likely to meet their primary endpoints, remarkably, studies from LMICs were published in journals with lower impact factors, with a median of 7 versus $21^{4}$. This study highlights the fact that current research in oncology does not match the global cancer burden and that there is a stark pervasive funding and publication bias against LMICs. The authors suggest that building research capacity is urgently needed throughout the world.

It is encouraging that the scientific community in HICs has begun to discuss this topic in major journals, which in the past was considered taboo or an uncomfortable truth. I have been encouraged to study the issue by my forward-thinking department and by a global capacity-building program for Latin American investigators called the Clinical Research Institute sponsored by the American Society of Hematology 5 . We must continue to do our part. We must keep the conversation on research equity going, attract attention from HICs to the issue, and find efficient ways to address it. We should encourage new generations of researchers from LMICs to become involved so that in the future, they are not limited by the status quo and can direct their efforts to improve the lives of people worldwide regardless of the color of their passport.

\section{Acknowledgments}

The authors would like to thank Professor David Gómez Almaguer for his critical review of the manuscript and for teaching us that research has no borders but our minds.

\section{Conflicts of interest}

The authors have no conflicts of interest to declare.

\section{Funding}

None.

\section{References}

1. World Bank. World Bank Country and Lending Groups. Vol. 2019. United States: World Bank; 2018.

2. Gómez-De León A, Pedraza PR, del Carmen Tarín Arzaga L, Bugarin-Estrada E, Gómez-De León D, Sung L, et al. Contributions to global hematology from low and middle-income countries: insights from ash 2018. Blood. 2021;7:622-31. doi: 10.1200/GO.20.00600.

3. Velin L, Lartigue JW, Johnson SA, Zorigtbaatar A, Kanmounye US, Truche $\mathrm{P}$, et al. Conference equity in global health: a systematic review of factors impacting LMIC representation at global health conferences. BMJ Global Health. 2021;6:e003455.

4. Wells CJ, Sharma S, Del Paggio JC, Hopman WM, Gyawali B, Mukherji $\mathrm{D}$, et al. An analysis of contemporary oncology randomized clinical trials from low/middle-income vs. High-income countries. JAMA Oncol. 2021;7:379-85.

5. Sung L, Rego E, Riva E, Elwood J, Basso J, Clayton CP, et al. Development and evaluation of a hematology-oriented clinical research training program in Latin America. J Cancer Educ 2017;32:845-9. 